SCIO. Revista de Filosofia, n. ${ }^{\circ}$ 19, Noviembre de 2020, 27-62, ISSN: 1887-9853

\title{
PROTECCIÓN Y PRINCIPIO DE NON-REFOULEMENT EN LA UNIÓN EUROPEA ${ }^{1}$
}

\author{
PROTECTION AND PRINCIPLE OF \\ NON-REFOULEMENT IN THE EUROPEAN UNION
}

\begin{abstract}
Ángeles Solanes Corella $a^{*}$
\end{abstract}
Fechas de recepción y aceptación: 9 de mayo de 2020 y 27 de octubre de 2020

DOI: 10.46583/scio_2020.19.720

Resumen: Un principio fundamental vinculado al derecho de asilo es el de no devolución a un tercer Estado en el que exista peligro para la vida o la libertad del solicitante. Dicha regla se encuentra positivizada en el artículo 33 de la Convención de Ginebra de 1950 y desde este instrumento se ha incorporado tanto al Sistema Europeo Común de Asilo (SECA) como a las diferentes legislaciones nacionales, entre ellas, la española. Sin embargo, la especial situación a la que se enfrenta la Unión Europea ha hecho que este principio haya sufrido diversas vulneraciones y que existan intentos de convertirlo más en una directriz que en una norma de obligado cumplimiento. El objetivo de este estudio es insistir en que la no devolución no debe considerarse una norma de soft law, sino que el derecho positivo deja constancia de su carácter vinculante y obligatorio para los Estados parte de la mencionada Convención

\footnotetext{
a Departamento de Filosofía del Derecho y Política. Facultad de Derecho. Universitat de València.

* Correspondencia: Universitat de València. Facultad de Derecho. Departamento de Filosofía del Derecho y Política. Avenida dels Tarongers, s/n. 46022 Valencia. España.

E-mail: angeles.solanes@uv.es

${ }^{1}$ Este artículo ha sido realizado en el marco del proyecto I+D+i PID2019-105018RB100 "Racismo y Discriminación: los Derechos Humanos bajo amenaza", Ministerio de Ciencia e Innovación.
} 
y tiene que respetarse unido a una adecuada definición de la noción de tercer país seguro. Solo así es posible garantizar la seguridad jurídica tan necesaria en el ámbito del asilo.

Palabras clave: Unión Europea, derecho de asilo, principio de nonrefoulement, SECA, tercer país seguro

Abstract: A fundamental principle linked to the right of asylum is that of non-refoulement to a third State, where there is danger for the applicant's life or freedom. This principle is positivised in the article 33 of the Geneva Convention of 1950 and, through this instrument, it has been incorporated into both the European regional system and the Common European Asylum System (CEAS). However, due to the special situation that the European Union is facing, non-refoulement has suffered setbacks. The objective of this study is to insist that nonrefoulement should not be considered as a soft law norm, but rather that the positive law establishes its binding and obligatory nature for the State parties to the aforementioned Convention. In addition, nonrefoulement must be respected, along with an adequate definition of the concept of a safe third country. Only this way is it possible to guarantee the much-needed legal security in the field of asylum.

Keywords: European Union, right of asylum, principle of non-refoulement, CEAS, safe third country

\section{§1. LA MOVILIDAD HUMANA: MIGRACIÓN, ASILO Y REFUGIO EN LA UE}

La movilidad humana, aunque no existe un concepto unánimemente aceptado, hace referencia a la noción de flujos mixtos que proporciona la Organización Internacional para las Migraciones que considera tales "los movimientos de población complejos incluidos los refugiados, solicitantes de asilo, migrantes económicos y otros migrantes" (IOM, 2004: 8, 31 y 42). Esa misma definición es la que mantiene el ACNUDH (2014: 4) cuando habla de migrante internacional para referirse "a cualquier persona que se encuentre fuera de un Estado del que sea ciudadano o nacional o, en el caso de las personas apátridas, de su Estado de nacimiento o residencia habitual. El término incluye a los migrantes que tienen la intención de trasladarse de forma 
permanente o temporal y tanto a los que se trasladan de manera regular o documentada como a los migrantes en situación irregular". Esta conceptualización genérica aglutina dentro de un mismo fenómeno realidades que son muy diversas, desde las denominadas causas económicas hasta los motivos de persecución dentro de una amplia variabilidad de factores (Sassen 2013 y 2014). Incluso en esos supuestos simplistamente diferenciados como económicos o no, existen muchas variables. En ese sentido, por ejemplo, descartado el sueño de la migración cero, por su imposible consecución práctica (aunque las situaciones de irregularidad persisten), el sistema de migración oportuna, precisa o deseada permite intentar adaptar los flujos migratorios a las necesidades básicamente económicas, pero también sociales, en un contexto internacional de competencia de trabajo especializado. Esta alternativa responde a pautas altamente tecnocráticas, pero al mismo tiempo funciona con medios arbitrarios que permiten multiplicar de forma estratificada los diferentes estados legales de los sujetos que coinciden en un mismo espacio político vigilando los límites entre las diferentes posiciones (Mezzadra y Nielson, 2014: 16). En cada uno de los casos, a la rúbrica de migración falsamente económica o calificada se asigna una situación jurídica u otra sin tomar en consideración las causas que la producen (Atak y Crépeau, 2014) y se obvia la gran pregunta acerca de si es lo mismo hablar de migraciones que de asilo.

Ciertamente, distinguir estas situaciones es fundamental. Dentro de los diferentes desplazamientos a nivel internacional de personas, a efectos del acceso a un estatuto jurídico u otro, es imprescindible diferenciar entre migración y asilo. En ese sentido, se hace referencia a la inmigración (desde la visión nada neutra de los Estados que reciben a extranjeros), cuando se apela al proceso por el cual los no nacionales de un Estado entran en él con el propósito de instalarse desde una dimensión más de carácter demográfico o sociológico. En cambio, el asilo, como concepto de construcción jurídica, alude a la protección concedida por un Estado a un extranjero en su territorio contra el ejercicio de la jurisdicción por el Estado de origen (Morgades, 2016: 231-235). Esta distinción inicial es primordial, ya que se trata de situaciones jurídicamente diferentes que exigen políticas y normativas diversas, por una parte, las de inmigración (concretadas en las denominadas normativas de extranjería) y, por otra, las de asilo. Ambas obedecen a realidades diferenciales 
en las cuales no debe rivalizarse por importancia, ni priorizar una en detrimento de la otra.

Aunque las nociones de asilo y refugio cuentan con importantes raíces históricas y son conocidas en el derecho internacional, se siguen utilizando, a menudo, como sinónimo, cuando en realidad no lo son, ni tampoco son los únicos mecanismos que posibilitan la protección de las personas. En el ámbito internacional son complementarios el derecho internacional de los derechos humanos y el derecho internacional humanitario, y con ellos el derecho internacional del asilo y el refugio en la medida en que asegura el ejercicio de un derecho humano y, al mismo tiempo, resulta aplicable en contextos de conflicto armado junto a las reglas específicas humanitarias.

El asilo puede considerarse como "la protección que un Estado concede en su territorio o en otro lugar bajo el control de algunos de sus órganos a una persona que viene a buscarlo". En ese sentido el asilo es diferente del estatuto de refugiado, ya que, mientras el primero constituye la institución de protección, el segundo se refiere a una de las categorías de individuos que, entre otros, se benefician de dicha protección. La Convención sobre el Estatuto de los Refugiados, aprobada en Ginebra el 28 de julio de 1951 (en adelante la Convención), y el Protocolo sobre el Estatuto de los Refugiados, adoptado en Nueva York el 31 de enero de 1967 (en adelante el Protocolo), constituyen las dos disposiciones de referencia a nivel internacional respecto al derecho de asilo que han sido ratificadas por todos los Estados de la Unión Europea. Aun siendo conscientes de esta distinción, existe una tendencia emergente, desarrollada entre los Estados europeos, de desdibujarla. Así se restringe el uso del término asilo a los refugiados, en el sentido que lo invoca la Convención, al desarrollar instituciones alternativas de protección entre las que se encuentran la protección temporal y la subsidiaria (Gil-Bazo, 2015).

Atendiendo al artículo 1 de dicha Convención, se considera refugiado a una persona que se encuentra fuera del país de su nacionalidad (o que carece de nacionalidad) y que por un temor fundado de ser perseguido por los motivos que se especifican (raza, religión, nacionalidad, pertenencia a determinado grupo social u opiniones políticas) no puede o no quiere volver a dicho Estado y se encuentra en una situación de necesidad de protección internacional. El estatuto de refugiado es, por tanto, el estatuto jurídico internacional previsto 
en la Convención que en el mencionado artículo concreta las cláusulas de inclusión o ámbito de aplicación personal, el ámbito de aplicación temporal y espacial, las cláusulas de cese del estatuto y las de exclusión.

Aunque el asilo y el refugio son dos instrumentos de protección internacional que se aplican a personas que han huido de sus Estados de origen, estas nociones no dan cuenta de la gran complejidad de la movilidad humana. Esta hace referencia también a los flujos migratorios y pone en evidencia que las causas por las que se realiza dicha movilidad, en este supuesto concreto por las que se huye, son relevantes desde el punto de vista normativo. En la práctica, los límites son difusos y dan lugar a gran cantidad de problemas a la hora de concretar, y sobre todo asegurar, la protección internacional en el contexto de los denominados flujos mixtos.

La restrictiva definición que recoge la Convención y la necesidad de ir adaptándola a esas nuevas realidades, que no fueron tomadas en consideración en el momento en que se adoptó esta, se han ido corrigiendo a través de una interpretación extensiva. En efecto, la interpretación evolutiva de los conceptos jurídicamente indeterminados que contiene la mencionada definición se ha ido ampliando desde la interpretación progresiva y dinámica de los Derechos Humanos en el Derecho internacional (Fiddian-Qasmiyeh, Loescher, Long y Sigona, 2014).

En esa línea, los sistemas regionales de protección de los derechos humanos han ido adoptando instrumentos garantistas que han servido para asegurar los derechos de las personas refugiadas. En el ámbito del Consejo de Europa, es fundamental la actividad del Tribunal Europeo de Derechos Humanos (TEDH) en aplicación del Convenio Europeo de Derechos Humanos (CEDH). Como se examinará más adelante, el CEDH ha favorecido una especial protección de los demandantes de asilo y los refugiados, aunque no contemple dicho derecho propiamente, al salvaguardar, entre otros, el derecho a no sufrir tortura o tratos inhumanos o degradantes (artículo $3 \mathrm{CEDH}$ ); el derecho a la libertad deambulatoria (artículo $5 \mathrm{CEDH}$ ); y el derecho a un recurso efectivo (artículo $13 \mathrm{CEDH}$ ) (Bossuyt, 2010).

En el contexto de la Unión Europea, el Tribunal de Justicia de la Unión Europea (TJUE), tras la atribución para el desarrollo de una política común de asilo de competencias, conferida por el Tratado de Ámsterdam (que entró en 
vigor en 1999), también ha desarrollado una labor garantista en la supervisión del artículo 18 de la Carta de Derechos Fundamentales de la Unión Europea (CDFUE) que recoge el derecho de asilo y en la articulación e implementación del Sistema Europeo Común de Asilo (SECA) (Peers, 2016).

La Unión Europea pretende establecer una política común en materia de asilo, protección subsidiaria y protección temporal que permita ofrecer un estatuto apropiado a los nacionales de un tercer país que necesiten protección internacional y garantizar el respeto del principio de no devolución. Esta política, en la línea de las obligaciones internacionales de los Estados miembros, deberá ajustarse a la Convención y al Protocolo. Ni en el Tratado de Funcionamiento de la Unión Europea (en concreto en los artículos 67. 2, 78 y 80 del TFUE), ni en la Carta de los Derechos Fundamentales de la Unión Europea (artículo 18 CDFUE) como base jurídica en esta materia se definen los términos asilo y refugiado, sino que ambos documentos se refieren específicamente a la Convención y a su Protocolo como normas básicas.

Precisamente en este contexto europeo, se centra este estudio para intentar analizar la relevancia de uno de los principios fundamentales vinculados al asilo y el refugio: el non-refoulement. El amplio entramado normativo al que ha dado lugar el SECA, sus continuas reformas y las que se encuentran en estos momentos en discusión no han permitido superar dos restricciones endémicas: el deseo de restringir el derecho de asilo a la mínima expresión y el incumplimiento manifiesto de los Estados europeos de las obligaciones dimanantes de las disposiciones normativas de Derecho internacional que resultan aplicables.

Entre los principales instrumentos jurídicos en el ámbito de la Unión Europea cabe señalar: en primer lugar, los diferentes actos normativos del Parlamento Europeo y del Consejo, de 26 de junio de 2013, entre ellas, el Reglamento (UE) n. ${ }^{\circ}$ 603/2013, relativo a la creación del sistema Eurodac para la comparación de las impresiones dactilares para la aplicación efectiva del Reglamento (UE) n. ${ }^{\circ} 604 / 2013$, por el que se establecen los criterios y mecanismos de determinación del Estado miembro responsable del examen de una solicitud de protección internacional presentada en uno de los Estados miembros por un nacional de un tercer país o un apátrida, y a las solicitudes de comparación con los datos de Eurodac presentadas por los servicios de 
seguridad de los Estados miembros y Europol a efectos de aplicación de la ley, y por el que se modifica el Reglamento (UE) n. ${ }^{\circ}$ 1077/2011, por el que se crea una Agencia europea para la gestión operativa de sistemas informáticos de gran magnitud en el espacio de libertad, seguridad y justicia (refundición, conocido como Reglamento Eurodac); el Reglamento (UE) n. ${ }^{\circ}$ 604/2013, por el que se establecen los criterios y mecanismos de determinación del Estado miembro responsable del examen de una solicitud de protección internacional presentada en uno de los Estados miembros por un nacional de un tercer país o un apátrida (texto refundido, conocido como Reglamento de Dublín III); la Directiva 2013/33/UE, por la que se aprueban normas para la acogida de los solicitantes de protección internacional; la Directiva 2013/32/UE, sobre procedimientos comunes para la concesión o la retirada de la protección internacional. Y, en segundo lugar, la Directiva 2011/95/UE del Parlamento Europeo y del Consejo, de 13 de diciembre de 2011, por la que se establecen normas relativas a los requisitos para el reconocimiento de nacionales de terceros países o apátridas como beneficiarios de protección internacional, a un estatuto uniforme para los refugiados o para las personas con derecho a protección subsidiaria y al contenido de la protección concedida; y la Directiva 2001/55/ CE del Consejo, de 20 de julio de 2001, relativa a las normas mínimas para la concesión de protección temporal en caso de afluencia masiva de personas desplazadas y a medidas de fomento de un esfuerzo equitativo entre los Estados miembros para acoger a dichas personas y asumir las consecuencias de su acogida.

El artículo 2 d) de la mencionada Directiva 2011/95/UE, en su texto consolidado, ofrece la definición legal de refugiado en la UE y entiende por tal "un nacional de un tercer país que, debido a fundados temores a ser perseguido por motivos de raza, religión, nacionalidad, opiniones políticas o pertenencia a determinado grupo social, se encuentra fuera del país de su nacionalidad y no puede o, a causa de dichos temores, no quiere acogerse a la protección de tal país, o un apátrida que, hallándose fuera del país donde antes tuviera su residencia habitual por los mismos motivos que los mencionados, no puede o, a causa de dichos temores, no quiera regresar a él, y al que no se aplica el artículo 12". 
Buena parte de estas disposiciones han sido sometidas a modificaciones que están siendo discutidas con importantes debates y retrocesos que evidencian la dificultad de legislar en esta materia. Sin entrar en detalle respecto a las reformas en curso, conviene tener en cuenta que buena parte de las disposiciones mencionadas no entraron en vigor hasta julio de 2013, de tal manera que su transposición se aplazó hasta mediados de julio de 2015, coincidiendo con el punto álgido de la mal denominada "crisis migratoria o de los refugiados". Ya desde la Agenda Europea de Migración (mayo 2015) se contemplaban medidas complementarias para reformar el SECA que, tras ser presentadas en mayo y en julio de 2016 en sendos paquetes de propuestas legislativas, se siguen examinando, respecto a cuestiones fundamentales como, entre otras, las medidas para simplificar, aclarar y reducir los procedimientos de asilo para ofrecer unas garantías comunes a los solicitantes de asilo; garantizar unas normas más estrictas para combatir abusos, incluida una lista común de países de origen seguros; los mecanismos para determinar quién reúne los requisitos para obtener la protección internacional a fin de lograr una mayor convergencia de las tasas de reconocimiento y las formas de protección; y la incorporación de disposiciones más restrictivas para sancionar los movimientos secundarios de los solicitantes y llevar a cabo con carácter obligatorio revisiones del estatuto de protección aun en el caso de los refugiados reconocidos.

Un aspecto básico que muestra la debilidad del SECA es el funcionamiento de los programas de reubicación y los de reasentamiento. Así, por ejemplo, se activaron los mecanismos de reubicación de emergencia para personas necesitadas de protección internacional propuestos por la Comisión con la finalidad de ayudar a Italia y Grecia. Esta propuesta se adoptó por el Consejo en septiembre de 2015, previa consulta al Parlamento, y fue avalada por el TJUE en la sentencia de 6 de septiembre de 2017. Sin embargo, si bien la reubicación permite la puesta en práctica del principio de solidaridad y de reparto equitativo de la responsabilidad del artículo 80 del TFUE, la realidad es que se ha concretado lentamente en tasas inferiores a las esperadas. En cuanto al Marco de Reasentamiento de la Unión, destinado a concretar normas comunes en la Unión sobre la admisión de nacionales de terceros países, incluido el apoyo financiero a los esfuerzos en materia de reasentamiento en los Estados 
miembros, como complemento de los programas multilaterales y nacionales de reasentamiento ad hoc vigentes, a pesar de los acuerdos intermedios, las negociones no han concluido, al igual que ha ocurrido con el resto de medidas legislativas del sistema.

En este contexto, una de las evidencias de esa política de retroceso del derecho de asilo, o de su desnaturalización al sufrir también el proceso de mercantilización de los derechos a pesar de ser un derecho humano fundamental y universal (De Lucas, 2016: 23), es la sistemática tensión a la que es sometido el principio de no devolución al intentar alejarlo de su dimensión de ius congens para aplicarlo desde una perspectiva de soft law.

El objetivo de este trabajo es, precisamente, insistir en que la no devolución no debe considerarse una norma de soft law, sino que el derecho positivo deja constancia de su carácter vinculante y obligatorio para los Estados parte de la mencionada Convención y tiene que respetarse unido a una adecuada definición de la noción de tercer país seguro. Solo así es posible garantizar la seguridad jurídica tan necesaria en el ámbito del asilo que permitirá reforzar el SECA.

\section{§2. NECESIDAD DE PROTECCIÓN Y PRINCIPIO DE NO DEVOLUCIÓN}

Junto al concepto de refugiado, la Convención en su artículo 33 concreta el denominado principio de non-refoulement, en virtud del cual los Estados parte no podrán “por expulsión o devolución, poner en modo alguno a un refugiado en las fronteras de territorios donde su vida o su libertad peligre por causa de su raza, religión, nacionalidad, pertenencia a determinado grupo social, o de sus opiniones políticas".

El principio de non-refoulement se recoge también en otros instrumentos del ámbito universal y regional, entre ellos: el artículo 16.1 de la Convención de las Naciones Unidas sobre la Protección de las Desapariciones Forzosas; el artículo 22.8 de la Convención Americana de los Derechos Humanos de 1969; el artículo 13.4 de la Convención Interamericana para prevenir y sancionar la tortura; el artículo 2.2 de la Convención de la Unión Africana sobre los aspectos específicos de los problemas de los refugiados en África de 1969; 
y el artículo 12.3 de la Carta Africana de Derechos Humanos y de los Pueblos de 1981. En el ámbito de la UE la gran red regulativa a la que ha dado lugar el SECA ha tomado en consideración este principio, por ejemplo, en la mencionada Directiva 2013/32/UE, en el Reglamento 656/2014 del Parlamento Europeo y del Consejo, de 15 de mayo de 2014, por el que se establecen normas para la vigilancia de las fronteras marítimas exteriores en el marco de la cooperación operativa coordinada por Frontex y en el Reglamento 2016/1624 del Parlamento Europeo y del Consejo, de 14 de septiembre de 2016, sobre la Guardia Europea de Fronteras y Costas (Vedsted-Hansen, 2015).

Este principio se encuadra en la definición de refugiado que ofrece la Convención poniendo especial énfasis en la dimensión individual de las personas que huyen ante el riesgo de sufrir persecuciones y se relaciona directamente con la necesidad de protección que está conectada, a su vez, con la idea de Derechos Humanos. De esta manera, el refugiado está protegido por el derecho inherente al principio de non-refoulement, que no permite la devolución si su vida o su libertad están amenazadas. Dicho enfoque encaja con la aproximación también individual a la protección de los Derechos Humanos, íntimamente conectada a la dignidad de la persona, que tras la II Guerra Mundial se refleja en la Declaración Universal de Derechos Humanos (Pons, 1998).

El principio de non-refoulement ha sido considerado por la doctrina como un principio de Derecho Internacional general que permitiría conectar el régimen internacional del asilo y el refugio con el régimen de la protección de los Derechos Humanos (Morgades, 2016: 235). El principio de no devolución es una norma de ius cogens o norma imperativa que supone la protección desde el momento en el que una persona que necesita y pide protección, por las causas ya señaladas, se encuentra bajo la jurisdicción de un Estado seguro, hasta el momento en que se determine su estatuto de protección (Gross, 1984: 710).

Este principio ha sido reforzado, en cuanto norma de carácter imperativo, por su vinculación con otras disposiciones del estándar internacional mínimo de derechos humanos. Así, el recurso al artículo 3 de la Convención de las Naciones Unidas contra la Tortura, otros Tratos o Penas Crueles, Inhumanos o Degradantes; al artículo 7 del Pacto Internacional de Derechos Civiles y Políticos, y al artículo 3 del Convenio Europeo de Derechos Humanos y Libertades Fundamentales, ha permitido conectar este principio con el temor a 
ser sometido a tortura o a tratos inhumanos o degradantes, que constituyen una prohibición absoluta según la jurisprudencia de los órganos de garantía de dichos convenios (Mariño, 2015).

Ahora bien, la difícil combinación, ya apuntada, entre el régimen jurídico de asilo y refugio y el de extranjería en el ámbito de la inmigración, ha tensionado la aplicación de este principio poniendo, aparentemente, en tela de juicio su alcance. En efecto, el crecimiento de los flujos migratorios y, en concreto, la denominada incorrectamente como "crisis de los refugiados" ha supuesto que determinados Estados hayan incumplido sus obligaciones respecto al asilo, sin llegar siquiera muchas veces a un análisis específico de las circunstancias de la persona solicitante. En el contexto europeo, dicha crisis ha puesto de relieve la estrecha relación estructural entre el control de las fronteras exteriores y la política común de inmigración y asilo. Así, se han establecido medidas excepcionales para determinados Estados como Italia y Grecia por ejemplo, con la Decisión (UE) 2015/1601 del Consejo, de 22 de septiembre de 2015, por la que se establecen medidas provisionales en el ámbito de la protección internacional en beneficio de Italia y Grecia; y con la Decisión (UE) 2015/1523 del Consejo, de 14 de septiembre de 2015, relativa al establecimiento de medidas provisionales en el ámbito de la protección internacional en favor de Italia y Grecia. Con este tipo de medidas se intentaba afianzar, también, que el SECA se asienta en la solidaridad entre los Estados miembros y la distribución equitativa de las solicitudes, pero al mismo tiempo es imposible obviar que subyace la idea de control migratorio. Estas previsiones no han tenido el resultado esperado, de tal manera que, han puesto una vez más en evidencia la debilidad de esa solidaridad y la prevalencia de las ideas de vigilancia y seguridad.

Esa precariedad en la forma de actuación conjunta dentro del SECA por parte de los diferentes Estados se pone de manifiesto en el hecho de que en este caso ha sido necesaria la intervención del TJUE. En la sentencia Comisión/ Polonia, Hungría y República Checa (Mecanismo temporal de reubicación de solicitantes de protección internacional) (C-715/17, C-718/17 y C-719/17), de 2 de abril de 2020, el Tribunal estimó los recursos por incumplimiento interpuestos por la Comisión contra estos tres Estados miembros al objeto de que se declarase que habían incumplido sus obligaciones dimanantes del 
derecho de la Unión al no haber comunicado, a intervalos regulares y, como mínimo, cada tres meses, un número adecuado de solicitantes de protección internacional que podían reubicar de forma rápida en sus respectivos territorios y, como consecuencia, no haber ejecutado las obligaciones subsiguientes en materia de reubicación que les incumbían. El Tribunal consideró que habían incumplido los diferentes Estados las obligaciones dimanantes de las mencionadas decisiones.

Es fundamental insistir, respecto a la cuestión de la necesidad de garantizar la protección de las personas, pero también los principios vigentes en el ámbito de la extranjería (seguridad y control), en el hecho de que el TJUE entendió que, en virtud de las citadas decisiones de reubicación, debía tomarse en consideración la seguridad nacional y el orden público durante todo el procedimiento de reubicación, hasta el traslado efectivo del solicitante de protección internacional. A este respecto, el Tribunal estimó que debía reconocerse un amplio margen de apreciación a las autoridades competentes de los Estados miembros de reubicación al determinar si había motivos razonables para considerar que un nacional de un país tercero susceptible de reubicación constituía un peligro para la seguridad nacional o el orden público en su territorio. Sobre esta cuestión, el TJUE consideró que el concepto de "peligro para la seguridad nacional o el orden público", a los efectos de las decisiones de reubicación, debe interpretarse en el sentido de que comprende tanto las amenazas actuales como las potenciales para la seguridad nacional o el orden público. Sin embargo, para invocar estos motivos, las autoridades debían basarse, tras un examen caso por caso, en elementos coherentes, objetivos y precisos que permitieran sospechar que el solicitante en cuestión constituía un peligro actual o potencial. E1 Tribunal insistía así en la importancia del examen individual que toma en consideración la situación y circunstancias concretas de la persona, en la línea señalada por la Convención. Desde esta perspectiva, el Tribunal declaró que, en el marco del procedimiento de reubicación, un Estado miembro no podía invocar perentoriamente el artículo 72 TFUE, solo como prevención general y sin demostrar la relación directa con un caso individual, para justificar la suspensión, o incluso el cese, del cumplimiento de las obligaciones que le incumben en virtud de las decisiones de reubicación. Esta interpretación, en mi opinión, reviste una especial importancia porque fortalece la exigencia de las obligaciones de los Estados miembros de acuerdo 
con el derecho comunitario, y las disposiciones internacionales en la materia, desde la necesidad de protección a partir del caso individual.

Esta interpretación del TJUE se relaciona con la tendencia que los Estados han tenido a apelar a la protección de la seguridad sin realizar un análisis específico de las circunstancias de la persona solicitante. El hecho de determinar el riesgo de la persona según sus circunstancias personales no supone necesariamente que el estatuto de refugiado tenga que estar basado en hechos totalmente personalizados. Si se interpreta de esta manera el concepto de refugiado, se establece una separación insuperable entre el régimen internacional del refugio y el asilo y el de los Derechos Humanos, es decir, una reducción del contexto interpretativo del principio de non-refoulement y de la definición de refugiado (Chimni, 1998: 352-355).

Desde el estándar mínimo internacional de Derechos Humanos y el régimen de refugio y asilo en dicho ámbito internacional el concepto de refugiado en la actualidad debe tomar en consideración la necesidad de protección, junto a la persecución, que se relaciona con la garantía de derechos básicos. Asimismo, no puede obviarse la perspectiva subjetiva que permite tener en cuenta la especial vulnerabilidad de algunos colectivos de personas, entre ellos, mujeres que se encuentran en determinadas circunstancias, niños, ancianos, familias, etc. (Morgades, 2016: 240).

La insistencia desde la Unión Europea en presentar de forma conjunta su política común de inmigración y asilo, ha repercutido, a largo plazo, en una progresiva degradación del estatuto de refugiado, que ha culminado en una situación insostenible en la que se evidencia el fracaso de lo que podría considerarse una buena parte de los ideales que están en el origen del proyecto europeo (De Lucas, 2015: 21).

Algunos Estados miembros como Grecia e Italia, especialmente por su situación geográfica, se han visto sometidos a una enorme presión migratoria y han reclamado un reparto más equitativo de responsabilidades en materia de asilo, especialmente ante situaciones complejas de emergencia que afectan a la vida y la dignidad de las personas (Oberoi y Taylor-Nicholson, 2013: 173), sin embargo, la respuesta europea, más allá de la reubicación, ha sido incluso militar más que humanitaria, tensionando el principio de non-refoulement (Arteaga y González, 2015). 
Es imprescindible, por tanto, insistir en el carácter imperativo de dicho principio también cuando se dé una llegada de flujos masivos. Precisamente ante la dificultad material de tramitar las solicitudes de protección internacional en una situación de flujo masivo, se ha configurado en derecho internacional la institución de la "protección temporal" en cuya articulación es esencial, igualmente, el non-refoulement. Esto es lo que ocurre en el caso de los denominados "refugiados prima facie" que son aquellas personas que forman parte de flujos masivos de personas que huyen de sus países de origen por causas que hacen suponer que todas o la mayoría serán consideradas como refugiadas (Morgades, 2016: 238). En ese sentido, la ya desaparecida Comisión de Derechos Humanos entendió, de modo reiterado, que el non-refoulement es aplicable en el caso de flujos masivos, sin que pueda reinterpretarse a la baja ni pueda considerarse como derogable (Comisión de Derechos Humanos: 1998: $\S \S 5$ y 7).

Igualmente, ACNUR ha insistido en que el non-refoulement es un principio fundamental que debe respetarse escrupulosamente también en frontera (ACNUR, 2001: § 6), ya que, como se evidenciará más adelante, es una de las zonas de suspensión del derecho internacional sobre asilo y refugio que imposibilita el acceso material a dicho estatuto jurídico. Se pone así especial énfasis en una de las cuestiones básicas del asilo y el refugio: puesto que solo se puede solicitar dentro del Estado de recepción o en sus fronteras, es imprescindible asegurar la no devolución. En esa línea se ha pronunciado incluso el Consejo de Seguridad de las Naciones Unidas (Resolución 2240 (2015) de 9 de octubre de 2015, mantenimiento de la paz y la seguridad internacionales), que exhorta además a todos los Estados, que tengan la jurisdicción pertinente en virtud del derecho internacional y la legislación nacional, a que investiguen y enjuicien a todas las personas responsables de actos de tráfico de migrantes y trata de personas en el mar, según las obligaciones que les incumben en virtud del derecho internacional, en particular el derecho internacional de los derechos humanos y el derecho internacional de los refugiados.

Obviamente, el ejercicio del derecho de asilo y el respeto al principio de non-refoulement afectan al poder soberano de los Estados a la hora de concretar quién puede entrar en ellos o permanecer en sus fronteras, así como al tipo de estatuto jurídico (con las correspondientes limitaciones) del que podrá dis- 
frutar (McAdam, 2011: 29). Por eso, en ocasiones los Estados, incluso dentro del funcionamiento del sistema común, han reducido e incluso paralizado el acceso al estatuto de refugiado al confundir la necesidad que la Convención señala de determinar el riesgo de la persona según sus circunstancias personales, que se indicaba anteriormente, con la idea de que dicho estatuto debería estar basado en un conjunto de hechos totalmente personalizados, lo cual ha sido impracticable en general y muy especialmente ante la llegada de flujos masivos (De Lucas, 2015: 97-100).

Se ha optado en este contexto por hacer una aplicación no estricta del nonrefoulement que, como se evidenciará en los siguientes apartados, ha sido sistemáticamente corregida por la jurisprudencia. El principio de non-refoulement tiene carácter vinculante, es decir, no es una disposición de soft law en la cual hay una participación voluntaria, con un consenso entre los actores que permita una legitimidad y obligatoriedad, y sin un poder sancionador. Más bien al contrario, es imprescindible insistir en que se trata de una regla de hard law porque es jurídicamente exigible y su incumplimiento debe dar lugar a la sanción del sujeto infractor, que no es otro que el Estado que incumple su obligación de respetar dicho principio.

\section{§3. ÁmBito DE APLICACIÓN Y LÍMITES}

Una de las cuestiones básicas de la Convención en la garantía del principio de non-refoulement, junto al ámbito personal de aplicación, es el ámbito de aplicación territorial (ratione loci) que ha sido interpretado desde diferentes perspectivas. En efecto, el artículo 40 de la Convención, que contiene su cláusula de aplicación territorial, se refiere a la posibilidad de extender su aplicación a los territorios que no puedan formar parte de dicha Convención por no haber obtenido personalidad jurídica internacional (Gil-Bazo, 2011), pero no aclara la cuestión fundamental respecto al non-refoulement.

A partir del ámbito de aplicación territorial de la no devolución, quedan bajo la jurisdicción del Estado de recepción las personas que se encuentren en su territorio y fronteras, con independencia de su situación administrativa. Ello supone excluir a quienes no consigan alcanzar este espacio geográfico. 
Sin embargo, esta interpretación resulta extremadamente restrictiva a los efectos garantistas que la Convención persigue.

En el contexto europeo, la normativa del SECA ha insistido en esa aplicación territorial, de tal modo que, aunque en este acervo se recoja el nonrefoulement, no se contempla la posibilidad de aplicación extraterritorial. En efecto, la ya mencionada Directiva 2013/32/UE se refiere a las solicitudes de protección internacional presentadas en el territorio, con inclusión de la frontera, las aguas territoriales y las zonas de tránsito de los Estados miembros. En la misma línea el citado Reglamento 604/2013 (Dublín III) se aplica únicamente a las peticiones presentadas en uno de los Estados miembros, incluyendo sus fronteras. Según el artículo 3 del mencionado reglamento, las personas que huyan de la persecución u otros daños graves y consigan llegar a territorio europeo, solo podrán presentar su solicitud de protección en un único Estado de la Unión Europea, que estará obligado a estudiarla y cuya decisión será vinculante para los demás.

Además, dicha Directiva recoge el concepto de tercer país seguro, que es fundamental, puesto que respecto a este no opera el non-refoulement. Así, en su artículo 38 se establece que los Estados "solo podrán aplicar el concepto de tercer país seguro cuando las autoridades competentes tengan la certeza de que el solicitante de protección internacional recibirá en el tercer país un trato conforme a los siguientes principios:

- su vida o su libertad no están amenazadas por razón de raza, religión, nacionalidad, pertenencia a un grupo social particular u opinión política.

- no hay riesgo de daños graves tal como se definen en la Directiva 2011/95/UE.

- se respeta el principio de no devolución de conformidad con la Convención de Ginebra.

- se respeta la prohibición de expulsión en caso de violación del derecho de no ser sometido a torturas ni a tratos crueles, inhumanos o degradantes, establecido en el Derecho internacional.

- existe la posibilidad de solicitar el estatuto de refugiado y, en caso de ser refugiado, recibir protección con arreglo a la Convención de Ginebra”. 
Entre los Estados europeos solo podrán ser considerados seguros, según el artículo 39, aquellos que hayan ratificado la Convención de Ginebra y el Convenio Europeo de protección de los Derechos Humanos, que cumplan con las disposiciones de ambos y que tengan un procedimiento de asilo prescrito por la ley.

En este punto, la cuestión fundamental que debe plantearse de modo crítico es para qué sirve realmente la concreción de una lista de tercer país seguro. En la práctica, el empleo de dicho concepto permite devolver a las personas a países distintos del de origen donde se considera que obtendrán protección y estarán a salvo del retorno al país perseguidor, de acuerdo con lo establecido en el artículo 3.3 del Reglamento Dublín, de tal manera que se cumple con la obligación de protección. Este mecanismo ha suscitado diferentes opiniones. Una parte de la doctrina entiende que es necesario utilizar los expedientes de país tercero seguro y país de origen seguro, para la situación de los denominados refugiados en órbita y los abusos por parte de personas que deberían estar dentro del régimen de extranjería, en cuanto inmigrantes, y que intentar entrar en territorio europeo por la puerta que constituye el asilo. Si la persona en cuestión procede de un país seguro, no concurriría el requisito relativo a la persecución que exige la Convención, de tal manera que no se generaría ninguna obligación para los Estados parte (Hailbronner, 1993: 53-65). Esta acción de carácter preventivo para evitar el abuso de la institución del asilo estaba ya en la base de la articulación del SECA, de tal forma que la actuación abusiva se presenta casi como la regla general de actuación en lugar de una excepción. Desde estas posturas que reclaman la necesidad de catalogar como seguros o no los diferentes países, se recurre también a las conclusiones del Comité Ejecutivo de ACNUR, entre ellas la número 58 (1989, 40..$^{\circ}$ período de sesiones del Comité Ejecutivo) que se ocupa del denominado problema de los refugiados y los solicitantes de asilo que abandonan de manera irregular un país en que ya habían encontrado protección. En ella se establece, en el apartado $f$, que a tales personas se las podrá devolver a ese país si allí sí están protegidas contra la posibilidad de una devolución, y si se les permite permanecer y son objeto de un trato conforme a las normas humanitarias básicas hasta que se encuentre una solución duradera para ellas. 
Frente a esta opinión, otra parte de la doctrina, desde mi punto de vista más garantista con los derechos humanos y con las obligaciones internacionales vinculadas al asilo, advierte de los problemas en la utilización del concepto de tercer país seguro. Desde dicha noción puede no tomarse en consideración que la persona en cuestión puede ya haber establecido un vínculo territorial en un Estado miembro de tal manera que, aunque cumplan las exigencias derivadas del artículo 1 a) de la Convención, podrían ver rechazada la admisión a trámite de su solicitud o denegada si se ha presentado en un puesto fronterizo apelando a que proceden de un país tercero seguro. En realidad, como apunta Orejudo (2017: 466-468), este concepto se asienta, como el mecanismo de Dublín, en dos ideas que pueden ser cuestionadas. La primera tiene que ver con la exigencia, como se señalaba anteriormente, de que la persona que busca protección debe solicitarla en el primer Estado en que pueda estar a salvo, lo cual no es una exigencia propia de la Convención o el Protocolo, sino un requisito específico del SECA que puede incluso entenderse que desvirtúa la posibilidad real de elegir país de refugio. La segunda idea apela a la cuestión de que un Estado puede eludir la obligación de resolver las solicitudes de asilo si transfieren la responsabilidad de su tramitación a otro, por ejemplo, si se entiende que los países de tránsito en los que ha estado el potencial solicitante tienen un sistema efectivo de asilo. Como se evidencia en la práctica el recurso a este mecanismo se utiliza incluso cuando los países incumplen claramente los requisitos mínimos para ser considerados como seguros. Por todo ello, la utilización de esta noción puede entenderse más como un mecanismo de control, supervisión y selección de quienes entran en los Estados miembros de la Unión Europea, que como una forma de protección a los refugiados.

La consolidación de esta noción se presenta como otra pieza dentro del SECA para conseguir el objetivo fundamental de evitar que una persona solicite asilo en el país de su elección (el llamado "asylum shopping") o que se encuentre en la Unión Europea sin que ningún país tome la responsabilidad de examinar su solicitud (el llamado "orbiting”). Para ello el sistema Dublín establece tres principios básicos: 1) los solicitantes de asilo tienen solo una oportunidad para solicitarlo en la Unión Europea y, en caso de respuesta negativa, esta es reconocida por todos los estados miembros; 2) son los criterios de distribución establecidos por Dublín, y no la preferencia de los propios so- 
licitantes, los que determinan qué Estado miembro debe hacerse responsable de examinar cada solicitud; y 3) los solicitantes de asilo pueden ser "transferidos" al Estado miembro que les haya sido asignado. La puesta en práctica de esta propuesta ha generado múltiples inconvenientes y ha evidenciado que la finalidad formal que se dice perseguir no es la real.

Entre los problemas que han surgido pueden citarse, a modo de ejemplo, varios. En primer lugar, el sistema de Dublín no es equitativo, ya que ser registrado en el primer país de llegada implica no poder solicitar asilo en otro Estado miembro o, en caso de hacerlo, arriesgarse a ser transferido de vuelta. La responsabilidad recae de forma desproporcionada (al menos en teoría) sobre los países fronterizos. En segundo lugar, no es eficiente, puesto que los solicitantes no piden asilo en el país de llegada o, si lo hicieron, repiten en otro lugar porque los criterios de asignación de responsabilidad de Dublín no coinciden con las preferencias de los propios solicitantes. Por el hecho de huir no les es indiferente el lugar al que van, en ningún momento se toma en cuenta las preferencias personales. En tercer lugar, el sistema Dublín vulnera los derechos de los refugiados, ya que, el examen justo y eficiente de las solicitudes de asilo, como se verá en el análisis de la jurisprudencia al respecto, no está garantizado en todos los Estados miembros. Además, los criterios de asignación de responsabilidad se aplican de forma muy dispar, por ejemplo, no teniendo en cuenta la presencia de miembros familiares, aplicando muy restrictivamente la cláusula humanitaria y usando como principal criterio el primer país de llegada. Por último, este sistema es caro económicamente, por todos los sistemas que lleva aparejados para su funcionamiento y por los procedimientos relacionados con las peticiones de transferencia y los gastos asociados con la detención y retorno de aquellos que son reconocidos como refugiados (Solanes, 2014).

A partir de lo señalado, puede considerarse que las mencionadas disposiciones comunitarias no permiten proteger plenamente los derechos de las personas que serían potenciales solicitantes de asilo y, en su caso, refugiados en la dimensión externa de la UE. Además, el propio TJUE ha señalado que los Estados miembros no están obligados, en virtud del derecho de la Unión, a expedir un visado humanitario a las personas que deseen entrar en su territorio con la intención de pedir asilo, aunque en todo caso son libres de 
hacerlo sobre la base de su derecho nacional. El acervo comunitario establece únicamente los procedimientos y las condiciones para la expedición de visados para tránsito o estancias previstas en el territorio de los Estados miembros no superiores a 90 días. En este punto conviene recordar la sentencia del TJUE (Gran Sala) de 7 de marzo de 2017 (petición de decisión prejudicial planteada por el Conseil du Contentieux des Étrangers - Bélgica) - X, X/ État belge (Asunto C-638/16 PPU). Esta cuestión prejudicial fue planteada por el Estado belga a propósito de dos nacionales sirios y sus tres hijos, residentes en la ciudad de Alepo (Siria), respecto a los cuales dicho gobierno se negó a otorgarles un visado de validez territorial limitada solicitado por razones humanitarias ante la embajada belga en Beirut. La pretensión de esta familia era solicitar asilo en Bélgica. El Estado belga consideró que no estaba obligado, ni sobre la base del artículo 3 del CEDH ni en virtud del artículo 33 de la Convención de Ginebra, a admitir en su territorio a un nacional de un tercer país, siendo su única obligación a este respecto la de no devolver a ese nacional.

Sobre esta cuestión, resulta mucho más garantista la interpretación dada por el abogado general Mengozzi que mantiene que las decisiones controvertidas en cuanto a la aplicación del Código de visados Reglamento (CE) n. ${ }^{\circ}$ 810/2009 del Parlamento Europeo y del Consejo, de 13 de julio de 2009, por el que se establece un Código comunitario sobre visados (código de visados, DO L 243/1, de 15 de septiembre de 2009) deben hacerse en el sentido del artículo 51.1 de la CDFUE. Al adoptar dichas decisiones, las autoridades mencionadas estaban obligadas a respetar los derechos garantizados por la Carta. Además, los derechos fundamentales reconocidos en ella se garantizan a los destinatarios de los actos adoptados por tal autoridad con independencia de cualquier criterio de territorialidad. Así el artículo 25.1 a), del mencionado Reglamento debe interpretarse en el sentido de que "el Estado miembro al que un nacional de un tercer país ha solicitado la expedición de un visado de validez territorial limitada por razones humanitarias está obligado a expedir tal visado si existen motivos serios y probados para creer que la negativa a expedir tal documento tendrá como consecuencia directa exponer a dicho ciudadano a sufrir tratos prohibidos por el artículo 4 de la Carta, al privarle de una vía legal para ejercer su derecho a solicitar la protección internacional en ese Estado miembro. El hecho de que ese nacional de un tercer Estado carez- 
ca de vínculos familiares o de cualquier otra clase con ese Estado miembro no influye en modo alguno en esta respuesta" (conclusiones del abogado general Mengozzi presentadas en el asunto X C638/16 PPU, EU:C:2017:93, puntos 88, 89 y 107).

Las restricciones generalizadas en la concesión de visado y la imposibilidad de solicitar protección más allá de las fronteras de los Estados receptores obligan a los potenciales refugiados a utilizar las mismas vías inseguras que los inmigrantes, acrecentando los flujos mixtos. Las alternativas que ha buscado la UE han hecho que el principio de non-refoulement funcione en la práctica, como se ha indicado, más como una norma de soft law que de hard law.

Un buen ejemplo de esta política en el ámbito de la inmigración y el asilo es el cuestionado acuerdo con Turquía de 18 de marzo de 2016. Respecto a esta Declaración, el Tribunal General de la UE consideró que no tenía jurisdicción para conocer el recurso de anulación presentado contra ella (recurso interpuesto el 22 de abril de 2016, NF/Consejo Europeo. Asunto T-192/16), ya que, ni el Consejo Europeo ni otra institución de la UE, habían decidido sobre dicho acuerdo, puesto que este fue adoptado por los Estados miembros. Por ello, el Tribunal consideró que no podía entrar a examinarlo y desestimó el recurso (auto del Tribunal General de 28 de febrero de 2017, NF/Consejo Europeo, T-192/16, EU:T:2017:128). Por tanto, se permitió el reenvío a Turquía de los refugiados que hubieran llegado a Grecia, sin despejar las dudas acerca de las garantías respecto a los derechos de los solicitantes de asilo en dos puntos básicos. Por una parte, si Turquía puede ser considerado un tercer país seguro, aunque no haya ratificado el Protocolo de aplicación de la Convención, de tal manera que, solo se otorgaba protección a los refugiados procedentes de determinados Estados europeos en aplicación de la Convención; tampoco ha ratificado el Protocolo n. ${ }^{\circ} 4$ del Convenio Europeo de Derechos Humanos, que prohíbe las expulsiones colectivas, y existan deficiencias en su normativa nacional respecto al acceso a derechos básicos por parte de las personas refugiadas como se constata, por ejemplo, a través de la jurisprudencia del TEDH. Por otro lado, en la línea antes apuntada, surge el interrogante de si en Turquía se respeta, como es exigible desde las disposiciones internacionales en materia de asilo, el principio de non-refoulement. 


\section{§4. LA RELEVANCIA DE LA INTERPRETACIÓN JURISPRUDENCIAL}

Para reivindicar y garantizar el carácter central que tiene el principio de non-refoulement en la configuración del asilo y el refugio, sobre el que ha insistido entre otros ACNUR (2007) ante el manifiesto incumplimiento por parte de los Estados, es básica la función de la jurisprudencia en el ámbito europeo. Tanto el TJUE como el TEDH han supervisado la necesidad de respetar la no devolución a terceros países que no sean considerados seguros, insistiendo en el carácter vinculante de este principio y, al mismo tiempo, en la exigencia de garantizar los derechos de los solicitantes de asilo en los reenvíos entre los Estados miembros. Así, por ejemplo, a partir de la STEDH, MSS contra Bélgica y Grecia, de 21 de enero de 2011, en la que se condena a Grecia por violar el artículo 3 del CEDH y a Bélgica por aplicar el Reglamento Dublín sabiendo que Grecia no podía cumplir con sus obligaciones, se deja constancia, según el Tribunal, de que es imprescindible realizar un examen exhaustivo para comprobar que el Estado es seguro.

Por lo que se refiere al TJUE, un punto de referencia significativo en el respeto a la no devolución es el asunto N.S. y Otros, de 21 de diciembre de 2011, que vuelve sobre el concepto de país seguro. Las dos peticiones de decisión prejudicial tienen por objeto la interpretación, en primer lugar, del artículo 3, apartado 2, del Reglamento (CE) n. ${ }^{\circ}$ 343/2003 del Consejo, de 18 de febrero de 2003, por el que se establecen los criterios y mecanismos de determinación del Estado miembro responsable del examen de una solicitud de asilo presentada en uno de los Estados miembros por un nacional de un tercer país (DO L 50, p. 1), y en segundo lugar, de los derechos fundamentales de la Unión Europea, incluidos los derechos enunciados en los artículos 1, 4, 18, 19, apartado 2, y 47 de la Carta de los Derechos Fundamentales de la Unión Europea (en lo sucesivo, «Carta»), y, en tercer lugar, del Protocolo (n. ${ }^{\circ} 30$ ) sobre la aplicación de la Carta a la República de Polonia y al Reino Unido (DO 2010, C 83, p. 313). Dichas peticiones se suscitaron en el marco de litigios entre solicitantes de asilo que debían ser trasladados a Grecia en virtud del Reglamento n. ${ }^{\circ}$ 343/2003 y las autoridades, respectivamente, del Reino Unido e irlandesas. El tribunal mantiene que no se puede presuponer de forma irrefutable que el Estado responsable respeta los derechos fundamentales de la Unión Europea. Por ello, se dispone que no se podrá trasladar a un solicitante de asilo al Estado miembro 
responsable "cuando no se puedan ignorar que las deficiencias sistemáticas del procedimiento de asilo en ese Estado miembro constituyan motivos serios y acreditados para creer que el solicitante correrá un riesgo real de ser sometido a tratos inhumanos o degradantes" (TJUE, Asunto N.S. y Otros, 21 de diciembre de 2011 (C411/10 y C493/10). ECLI:EU:C:2011:865).

Como consecuencia de esta sentencia fueron suspendidos los traslados a Grecia y se modificó el artículo 3.2 del Reglamento Dublín III. Además, esta resolución considera equiparable las denominadas "deficiencias sistémicas" existentes en los Estados miembros responsables de examinar una solicitud de asilo y el "riesgo real" al que hace referencia el TEDH con relación al artículo $3 \mathrm{CEDH}$, por lo cual el TJUE entiende aplicable el artículo 4 CDFUE.

Un punto de inflexión en el fortalecimiento del principio de non-refoulement lo constituye el caso Hirsi Jamaa y otros contra Italia (TEDH, [GC], n. ${ }^{\circ}$ 27765/09, 23 de febrero de 2012), en el que el Tribunal insiste en la no devolución en el ámbito extraterritorial. Este supuesto hace referencia a un grupo de personas somalíes y eritreas procedentes de Libia que fueron detenidas en el mar y luego devueltas a Libia por las autoridades italianas. Los demandantes se quejaron, en particular, de que habían sido objeto de una expulsión colectiva, alegando asimismo que no existía un recurso efectivo disponible en Italia al que pudieran acudir. El Tribunal consideró que la expulsión de los solicitantes era colectiva, por tanto, contraria al artículo 4 del Protocolo n. ${ }^{\circ} 4$, y apreció la violación del artículo $3 \mathrm{CEDH}$ (prohibición de tratos inhumanos o degradantes), a los que se exponían los demandantes no solo si eran devueltos a Libia, sino también ante la amenaza de que lo fueran a sus países de origen. Además, entendió vulnerado el artículo $13 \mathrm{CEDH}$ (derecho a un recurso efectivo) junto con el artículo 3 de este (con especial mención al principio de no devolución $\S \S 135$ y 136), y con el artículo 4 del Protocolo n. ${ }^{\circ} 4$, ya que los solicitantes no habían podido obtener una revisión exhaustiva de sus quejas por una autoridad competente antes de que se ejecutase la expulsión (Solanes, 2017: 50-51).

El Tribunal, tras analizar el caso a la luz del artículo 33 de la Convención, y en su conexión ya indicada con el artículo $3 \mathrm{CEDH}$, entendió por unanimidad que la devolución de los solicitantes de asilo procedentes de Eritrea y de Somalia tras haber sido interceptados en alta mar por la guardia italiana 
y su envío a Libia en barcos militares italianos violaba la obligación de nonrefoulement (TEDH, Hirsi Jamaa y otros contra Italia [GC], §§ 134 y 135).

El TEDH consideró que los demandantes estaban dentro de la jurisdicción italiana, resultando así de aplicación el artículo $1 \mathrm{CEDH}$, aunque se tratara del traslado de extranjeros a un tercer Estado fuera del territorio nacional, en este supuesto, italiano. De esta manera, tanto el concepto de expulsión como el de jurisdicción se vinculaban directamente con el territorio nacional, de un Estado concreto que la ejercía, excepcionalmente, fuera de dicho territorio.

Con esta resolución, es necesario entender que las normas sobre salvamento de personas en el mar y las de lucha contra el tráfico de seres humanos imponen a los Estados el deber de cumplir con las obligaciones derivadas del principio de non-refolument. Así, cuando se intercepte una embarcación con personas migrantes debe ponerlas a salvo, proceder a la identificación de las personas y trasladarlas a un país seguro que, en la situación actual, debería entenderse que solo puede ser europeo (Arenas, 2016: 55)

En este supuesto, el TEDH, aun admitiendo la necesidad y dificultad de lo que considera como el necesario control de los flujos migratorios, llama la atención sobre la exigencia de respeto y garantía de los derechos de los extranjeros en todas las etapas del proceso. Igualmente apela a la obligación, reiterada en su jurisprudencia, de asegurarse del hecho de que los Estados que no sean parte del CEDH, que van a recibir a los extranjeros, hayan ratificado los tratados que configuran el estándar mínimo internacional de Derechos Humanos, lo cual como quedó demostrado en sede judicial, no ocurría en este caso (Bollo, 2013).

La importancia de esta resolución hace que una parte de la doctrina se plantee si puede ser considerada como una sentencia piloto en lo relativo a garantizar los derechos establecidos en el sistema europeo tanto en el caso de la inmigración como en el del asilo (De Castro, 2013). Con este asunto queda claro que la obligación de non-refoulement de los Estados persiste en el ámbito extraterritorial como una norma de hard law, tal como ha continuado manteniendo el TEDH en su jurisprudencia posterior, en casos como, por ejemplo, De Souza Ribeiro contra Francia [GC], n. ${ }^{\circ} 22689 / 07,13$ de diciembre de 2012; A. C. y otros contra España, n. ${ }^{\circ}$ 6528/11, 22 de abril de 2014; Sharifi y otros contra Italia y Grecia, . $^{\circ}$ 16643/09, 21 de octubre de 2014; 
Tarakhel contra Suiza [GC], n. ${ }^{\circ} 29217 / 12,4$ de noviembre de 2014; y N. D. y N. T. contra España, n. ${ }^{\circ} 8675 / 15$ y 8697/15, 3 de octubre de 2017 (aunque se verá más adelante la matización en esta última sentencia).

En esa línea se sitúa la mencionada interpretación del abogado general Mengozzi, que no coincide de momento con la sostenida por el TJUE aunque insista en la importancia del concepto de tercer país seguro. Mengozzi se remite al artículo $1 \mathrm{CEDH}$ que "contiene una «cláusula de jurisdicción» que funciona como criterio de activación de la responsabilidad de los Estados Parte en el CEDH por posibles infracciones de las disposiciones de dicho Convenio" (Conclusiones del abogado general Mengozzi, punto 97), aunque en el caso de la CDFUE haya que acudir al artículo 51.1 como se indicaba anteriormente.

Resulta preocupante, en el fortalecimiento del principio de no devolución a partir de la citada jurisprudencia, la interpretación más reciente que ha realizado el TEDH a propósito de las denominadas devoluciones en caliente. Con esta noción se alude a la práctica realizada en Ceuta y Melilla, así como desde islotes sujetos a la soberanía del Estado español que hace referencia a la actuación de las Fuerzas y Cuerpos de Seguridad del Estado y consiste en la entrega a las autoridades marroquís, por vía de hecho, de personas extranjeras que han sido interceptadas por dichos Cuerpos y Fuerzas en zona de soberanía española, sin seguir el procedimiento establecido normativamente ni cumplir las garantías internacionalmente reconocidas. Eso es lo que ocurrió en el caso N. D. y N. T. contra España, que se remonta al 13 de agosto de 2014, cuando ni siquiera esta práctica estaba recogida en ninguna disposición legal.

Estas devoluciones se consideran "en caliente" porque no siguen ningún procedimiento legal, son sumarias, en realidad ni siquiera responden al termino jurídico de devolución, solo es una forma común de designarlas. La Ley Orgánica 4/2015, de 30 de marzo, de Protección de la Seguridad Ciudadana, en su Disposición Final Primera estableció un régimen especial para Ceuta y Melilla en el intento de legalizar este tipo de prácticas. Dicha disposición expresamente mantiene: "los extranjeros que sean detectados en la línea fronteriza de la demarcación territorial de Ceuta o Melilla mientras intentan superar los elementos de contención fronterizos para cruzar irregularmente la frontera podrán ser rechazados a fin de impedir su entrada ilegal en España”. Además, 
en la misma norma se añade una Disposición Adicional Décima a la Ley Orgánica 4/2000, de 11 de enero, sobre derechos y libertades de los extranjeros en España y su integración social (la denominada comúnmente como ley de extranjería), vigente desde el 1 de abril de 2015, en la que se recuerda la necesidad de respetar la normativa internacional de Derechos Humanos y de protección internacional de la que España es parte, cuando se realice el rechazo en frontera, pero no se concreta un procedimiento con garantías. Por todo ello, las denominadas devoluciones en caliente, de facto, se han seguido produciendo en la valla fronteriza (Solanes, 2017).

En su sentencia de 3 de octubre de 2017, el TEDH sostuvo, por unanimidad, que se había violado el artículo 4 del Protocolo n. ${ }^{\circ} 4$ (prohibición de expulsión colectiva de extranjeros). El Tribunal señaló en particular que N. D. y N. T. fueron retirados y devueltos a Marruecos en contra de su voluntad y que las medidas de expulsión se tomaron en ausencia de una decisión administrativa o judicial previa. En ningún momento N. D. y N. T. estuvieron sujetos a un procedimiento de identificación por parte de las autoridades españolas. El Tribunal concluyó que, en estas circunstancias, se trataba de expulsiones colectivas. El TEDH también señaló por unanimidad que se había violado el artículo 13 (derecho a un recurso efectivo) del CEDH.

Sin embargo, en la sentencia de 13 de febrero de 2020, la Gran Sala del TEDH declara, también por unanimidad, que no ha habido vulneración del artículo 4 del Protocolo n. ${ }^{\circ} 4$ del Convenio y que no se ha violado el artículo $13 \mathrm{CEDH}$, considerado junto a dicho artículo 4 . Tras esta resolución cabe entender que las devoluciones en caliente pueden considerarse legales. De los argumentos de la Gran Sala para fundamentar el fallo, dos son fundamentales: $a$ ) los dos recurrentes se pusieron a sí mismos en una situación de infracción de la legalidad española, lo que justifica una medida de este tipo; y $b$ ) los recurrentes no utilizaron para entrar en España otros medios legales existentes y plenamente disponibles. Respecto al primer aspecto, conviene recordar la obviedad de que incluso en el caso de infracción de la normativa vigente persisten a las garantías jurídicas. En cuanto al segundo aspecto que hace referencia a la posibilidad de buscar alternativas legales para la entrada en España, la afirmación del Tribunal demuestra una importante falta de conocimiento de la realidad de la frontera sur española donde es sumamente difícil gestionar la posibilidad de una entrada legal. 
Tras este último pronunciamiento del TEDH queda todavía la posibilidad de que el Tribunal Constitucional considere esta práctica como inconstitucional. Para ello, debería pronunciarse en tal sentido a propósito de la mencionada Disposición Final Primera de la LO 4/2015 que trató de legalizar estas prácticas en la frontera. A diferencia de las posturas que mantienen que el Tribunal Constitucional debería seguir la línea establecida por el TEDH y avalar las devoluciones en caliente, desde mi punto de vista es posible sostener lo contrario, por varias razones.

El Tribunal Constitucional conoce las dificultades para las entradas legales, así como para acceder al asilo y a la protección internacional en la frontera sur. Por eso, lo fundamental, en mi opinión, es que se centre en la necesidad de aplicación de la normativa vigente en lo que a seguimiento del procedimiento se refiere, porque el hecho de que no exista un procedimiento de identificación por parte de las autoridades españolas, ni una decisión administrativa o judicial previa, equivale a negar la posibilidad de la tutela judicial efectiva. Esta necesidad de aplicación de la normativa vigente en materia de asilo y extranjería, desde la consideración de la realidad en la que esta se incardina, aseguraría la no vulneración de principios constitucionales como el de legalidad, prohibición de la arbitrariedad y seguridad jurídica.

A los efectos que ahora interesan, el Tribunal Constitucional no debe obviar la centralidad del derecho de asilo en esta cuestión. Las devoluciones en caliente son prácticas contrarias al artículo 33 de la Convención. Si estas devoluciones impiden la identificación de las personas que requieren protección internacional e imposibilitan su acceso a los procedimientos de asilo es imposible asegurar el non-refoulement.

\section{§5. A MODO DE CONCLUSIÓN}

El crecimiento de la movilidad humana hacia Europa en la última década y la ausencia de una política definida y delimitada de inmigración y asilo han facilitado la aplicación de medidas de seguridad también a las personas que huyen de la persecución y del peligro de sufrir daños graves. Esas medidas restrictivas de control de fronteras, unidas a la ausencia de cauces legales y 
seguros para acceder a la protección internacional desde fuera de Europa, han proyectado exponencialmente la acción de las redes delictivas de traficantes para acceder a territorio europeo y presentar la solicitud de protección. La frontera como uno de los baluartes nacionales persiste en cumplir su papel defensivo, manteniendo y alimentando la psicosis del miedo como justificación frente a medidas que vulneran derechos, exceptuando la legalidad hasta límites imprevisibles, y recurriendo a la violencia como medida reactiva casi inevitable ante dicho miedo (Solanes, 2016).

Al mismo tiempo, el aumento de los flujos ha colocado a Estados como Grecia e Italia en una situación que ha exigido la adopción de disposiciones especiales por parte de la UE. Estas previsiones no siempre han sido tan efectivas como se esperaba y han obligado a Estados, como el griego, a afrontar en solitario situaciones que exigían una respuesta contundente, en una línea humanitaria y garantista de los Derechos Humanos, por parte de todos los Estados miembros (Solanes y Delipetrou, 2017).

Ciertamente, como se ha evidenciado en este estudio, es necesario optar por una política de asilo distinta que pueda tomarse, con sus deficiencias, como otra posibilidad de gestión de las solicitudes de asilo frente a las exiguas cuotas europeas, ancladas en una visión básicamente temerosa y defensiva que compromete la no devolución y es más propia de lo que podría considerarse "una sinistrosis de inseguridad vinculada al cierre de las fronteras para proteger un mercado de trabajo siempre en crisis" que de las exigencias de las demandas de protección internacional (Naïr, 2016: 28).

Una de las consecuencias directas de la incapacidad de afrontar esa movilidad humana en clave de emergencia humanitaria y conforme a derecho, ha sido la de privar a los potenciales solicitantes de asilo de la garantía del nonrefoulement. En todo caso, no puede obviarse que los incumplimientos de las obligaciones vinculadas a la protección internacional no han comenzado con la mal denominada crisis de los refugiados, sino que esta lo que ha hecho es visibilizar y aumentar una praxis ya existente que se ha dado también en los casos de reubicación.

El principio de non-refoulement se sustenta en los convenios internacionales de Derechos Humanos, no solo se reconoce en la Convención y su Protocolo, sino también, como se ha señalado, en otros instrumentos. Así, por 
ejemplo, para garantizar la prohibición de tortura y tratos inhumanos o degradantes que se concreta en el artículo 3 CEDH y en el 4 CDFUE, es indispensable cumplir en el caso de los solicitantes de asilo la obligación de no devolución o retorno a Estados donde exista un riesgo real de sufrir tales torturas o tratos inhumanos o degradantes, sin que puedan establecerse excepciones al respecto. Igualmente, otros derechos deben tomarse en consideración, entre ellos el derecho a la libertad y seguridad (artículo $5 \mathrm{CEDH}$ ), el derecho a la vida privada y familiar del artículo $(8 \mathrm{CEDH})$ y el derecho a un recurso efectivo (artículo 13), así como la prohibición de expulsiones colectivas del artículo 4 del Protocolo n. ${ }^{\circ} 4$.

En este punto es fundamental insistir en la situación de desprotección en la que se encuentra el potencial solicitante de asilo desde el momento en que abandona su país hasta que consigue llegar a alguna de las fronteras en las que puede solicitar protección. Por eso, es básico que el principio de non-refoulement actúe tanto en el ámbito territorial como en el extraterritorial dentro del espíritu garantista que subyace en la Convención a pesar de ser deudora del tiempo histórico en el que surge y, por ello, adolecer de significativas deficiencias mejorables a través de una interpretación amplia.

En ese sentido, el primer supuesto de aplicación territorial cuando el solicitante se encuentre en el Estado receptor o en sus fronteras, parece revestir menor problema en la medida en que actúa el estándar ordinario de la Convención y la CDFUE en conexión con el CEDH. Conviene destacar que esta obligación de no devolución se aplica también, a tenor de la jurisprudencia analizada, en los reenvíos que se produzcan entre los Estados en el contexto del SECA y en la aplicación de la Declaración entre Turquía y la UE.

Asimismo, la prevalencia del principio de no devolución debe igualmente garantizarse en la frontera. Respecto a las mencionadas devoluciones en caliente, como ejemplo paradigmático de imposibilidad de acceder incluso a la petición de asilo en la frontera española, es preciso recordar que la cuestión que subsiste es si el Tribunal Constitucional tiene que seguir los argumentos de la sentencia del TEDH en el caso N. D. y N. T., con las consecuencias que ello supondría en cuanto a avalar dichas prácticas. La respuesta, desde mi punto de vista, como se ha sostenido, es negativa. Como señala el artículo 53 $\mathrm{CEDH}$, en relación con la protección de los Derechos Humanos reconocidos, 
ninguna de las disposiciones del Convenio se puede interpretar en el sentido de limitar o perjudicar aquellos derechos humanos y libertades fundamentales que podrían ser reconocidos conforme a las normativas de los Estados o en cualquier otro Convenio. Así puede entenderse que el CEDH es una garantía de mínimos, que en todo caso puede mejorarse con las legislaciones concretas de los Estados y otras disposiciones internacionales.

En ese sentido, el Comité de Derechos Humanos en las "Observaciones finales sobre el sexto informe periódico de España" (CCPR/C/ESP/CO/6), de 14 de agosto 2015, ya puso de manifiesto su preocupación por las devoluciones en caliente, a propósito de la reforma de la LODYLE. Expresamente el Comité le recomendó a España revisar la citada Ley de Protección de la Seguridad Ciudadana y garantizar que todas las personas que solicitan protección internacional tengan acceso a procedimientos de evaluación justos e individualizados, a la protección frente a la devolución sin discriminación y a un mecanismo independiente con autoridad para suspender las decisiones negativas. El Tribunal Constitucional, por tanto, tiene aún la oportunidad de salvar el error interpretativo del TEDH y declarar la inconstitucionalidad de las devoluciones en caliente para acudir a los procedimientos legales ya existentes que garanticen el derecho de asilo y el principio de non-refoulement.

En segundo lugar, por lo que se refiere a la aplicación extraterritorial, persisten las obligaciones que emanan de la no devolución, con la necesidad de comprobar si se cumplen los requisitos para ser considerado como un tercer país seguro, tal como apunta la jurisprudencia del TJUE y el TDEH. En la dimensión extraterritorial, con especial atención a las personas que sean interceptadas en alta mar, es aplicable la prohibición absoluta relativa a la tortura y las penas o tratos inhumanos o degradantes desde el CEDH y la prohibición de devolución de la CDFUE aunque se trate de afluencias masivas. La seguridad de las personas es prioritaria, debiendo desembarcar en un puerto seguro que les permita ejercer su derecho a solicitar la protección internacional y ser protegidos mediante la no devolución cuando existan los riesgos graves señalados, todo ello dentro de un contexto de seguridad jurídica.

Con todo, no puede negarse que la política de asilo desarrollada con el SECA ha contribuido, en buena medida, a fortalecer las fronteras físicas, a su externalización hacia terceros países (como en el caso de Turquía), pero 
sin asegurar que con ello subsistían las garantías necesarias para el ejercicio efectivo de los derechos; y, al mismo tiempo, ha acrecentado las fronteras documentales en relación con los visados. La verdadera pretensión que subyace a este tipo de prácticas es la de dificultar el acceso al territorio de los Estados de la Unión Europea y, con ello, la posibilidad de acceder al estatuto de refugiado. En este contexto, la consolidación de la noción de tercer país seguro, es un elemento indispensable para favorecer dicha dificultad que tiene que ver con la carga de la prueba en la práctica, donde ya no solo hay que demostrar la cuestión fundamental de la persecución que distingue la necesidad de protección en los casos de asilo, sino también que no se procede o se ha transitado por un "país seguro". En ese sentido, las solicitudes de personas que procedan de un país de origen que se considera seguro no pueden demostrar que se encuentran dentro del ámbito que ampara la Convención y el Protocolo, de tal manera que claramente no pueden entrar dentro de las disposiciones que todos los Estados establecen en el ámbito del SECA. Igualmente, si se trata de personas que podían haber obtenido asilo porque transitaron por un tercer país que se considera seguro, su solicitud será inadmitida a trámite.

La noción de país seguro no es la única que se ha utilizado para dificultar la concesión de protección, aunque sí la que tiene una mayor conexión con la centralidad que debería tener el principio de non-refoulement para asegurar aquella. Existen igualmente otras prácticas que también obstaculizan el acceso al derecho de asilo, entre ellas, los test de nacionalidad en los cuales se somete al solicitante a preguntas que, en buena medida, tienen que ver con su nacionalidad. En ese sentido, tener una nacionalidad de un país no miembro de la UE es, en principio, presupuesto de la concesión de protección con arreglo a las normas de la UE si se cumplen el resto de requisitos, pero la práctica evidencia que, además, la nacionalidad en concreto puede resultar determinante para la admisión a trámite. Así mismo, la aplicación del criterio de discreción razonable o la alternativa de reubicación dificultan también el asilo. Todo ello implica evitar las obligaciones que derivan del enfoque individualista propio de la Convención y su Protocolo que exigen atender a las circunstancias particulares de cada demandante de protección, con exámenes particulares en cada caso que aseguren la no discriminación por los diferentes motivos que se recogen en el artículo 3 de la Convención y en otras disposiciones de Derechos Humanos (Orejudo, 2017: 485). 
Los múltiples problemas que se han señalado respecto al funcionamiento real del SECA han debilitado hasta el extremo el principio de no devolución. La práctica de Estados miembros que sistemáticamente incumplen sus obligaciones, como se evidencia desde la jurisprudencia analizada, y la ausencia de una voluntad política clara de reforzar el principio de solidaridad, hace que los Estados incumplidores en lugar de salir perjudicados se vean, incluso, en la situación de que no se devuelva a su territorio a las personas cuyas solicitudes son responsables de examinar. En buena medida, resulta difícil negar que las disposiciones y los mecanismos del sistema de Dublín, en realidad, incentivan el incumplimiento por parte de los Estados miembros y abocan a la desobediencia a las personas necesitadas de protección (Den Heijer, Rijpma y Spijkerboer, 2016: 422). De ahí la insistencia en las múltiples reformas que se han propuesto sobre la normativa básica de Dublín y las diversas discusiones al respecto que no permiten que estas salgan adelante aunque en la práctica, y desde los inicios, se ha evidenciado que las modificaciones son imprescindibles para conseguir una mayor y mejor protección de las personas solicitantes de asilo.

En ese contexto de transformación del SECA, sin la garantía primaria que ofrece el principio de non-refoulement, entendida como obligación positiva del Estado receptor, el sentido del derecho de asilo, y en concreto del estatuto jurídico de refugiado, se desvirtúa. Ello es así porque la primera medida para proteger a las personas perseguidas es no devolverlas al lugar en el que son objeto de persecución, donde sus derechos más elementales pueden ser vulnerados de manera irreparable. Por eso el non-refoulement es, y debe seguir siendo en la práctica, un principio general de derecho internacional que vincula a los Estados, frente a todos los demás (erga omnes) y frente a la persona solicitante.

REFERENCIAS BIBLIOGRÁFICAS

ACNUDH (2014). Principios y directrices recomendados sobre los Derechos Humanos en las fronteras internacionales, consultado el 5/05/2020. Disponible en: <http://www.ohchr.org/Documents/Issues/Migration/OHCHR_ Recommended_Principles_Guidelines_SP.pdf $>$. 
ACNUR (2001). Protection of Refugees in Mass Influx Situations: Overall Protection Framework, Global Consultations on International Protection $\mathrm{EC} / \mathrm{GC} / 01 / 4$, de 19 de febrero.

ACNUR (2007). Opinión Consultiva sobre la aplicación extraterritorial de las obligaciones de no devolución en virtud de la Convención sobre el Estatuto de los Refugiados de 1951 y su Protocolo de 1967, 26 de enero.

Arenas, N. (2016). Flujos masivos de población y seguridad. La crisis de personas refugiadas en el Mediterráneo. Araucaria. Revista Iberoamericana de Filosofía, Política y Humanidades (36), 339-372.

Atak, I., Crépeau, F. (2014). Managing Migrations at the External Borders of the European Union: Meeting the Human Rights Challenges. Journal Européen des Droits de l'Homme (5), 591-622.

Arteaga, F., González, C. (2015). La respuesta militar a la crisis migratoria del Mediterráneo, ARI, Real Instituto El Cano (40).

Bollo, M. D. (2013). Push back, expulsiones colectivas y non refoulement. Algunas reflexiones a propósito de la sentencia dictada por la gran sala del TEDH en el caso Hirsi Jamaa y otros c. Italia (2012). En S. Torres (coord.), El Derecho internacional en el mundo multipolar del siglo XXI: obra homenaje al profesor Luis Ignacio Sánchez Rodríguez (pp. 647-666), Madrid: Iprolex.

Bossuyt, M. (2010). Strasbourg et les demandeurs d'asile: des juges sur un terrain glissant. Bruxelles: Bruylant.

Chimni, B. (1998). The Geopolitics of Refugee Studies: A View from the South. Journal of Refugee Studies (11, 4), 350-374.

Comisión de Derechos Humanos (1998). Human rights and mass exoduses, Resolución 1998/49, 17 de abril, E/CN.4/RES/1998/49.

De Castro, C. (2013). Tribunal Europeo de Derechos Humanos - TEDH Sentencia de 23.02.2012 (Gran Sala), Hirsi Jamaa e.a. c. Italia, 27765/09. “Artículo 3 y 13 del CEDH; Artículo 4 del Protocolo no 4 - Tortura y tratos inhumanos y degradantes - derecho a un recurso efectivo - prohibición de las expulsiones colectivas de extranjeros". Revista de Derecho Comunitario Europeo $(17,46), 1119-1135$. 
De Lucas, J. (2015). Mediterráneo: el naufragio de Europa. Valencia: Tirant lo Blanch.

De Lucas, J. (2016). Sobre el proceso de vaciamiento del derecho de asilo por parte de los Estados de la UE. Ars Iuris Salmanticensis. Tribuna de Actualidad (4), 21-27.

Den Heijer, M., Rijpma, J., Spijkerboer, T. (2016). Coercion, prohibition, and great expectations. The continuing failure of the Common European asylum System. Common Market Law Review (2), 419-451.

Fiddian-Qasmiyeh, E., Loescher, G., Long, K., Sigona, N. (ed.) (2014). The Oxford Handbook of Refugee and Forced Migration Studies. Oxford: Oxford University Press.

Gil-Bazo, M. T. (2011). Article 40. 1951 Convention. En A. Zimmermann (ed.), The 1951 Convention Relating to the Status of Refugees and its 1967 Protocol: a commentary (pp. 1567-1588), Oxford: Oxford University Press.

Gil-Bazo, M. A. (2015). Asylum as a General Principle of International Law. International Journal of Refugee Law (27, 1), 3-28.

Gros, H. (1984). Derechos Humanos, Derecho internacional humanitario y Derecho internacional de los refugiados. En Ch. Swinarski (ed.), Etudes et essais sur le droit international humanitaire et sur les principes de la Croix-Rouge en l'honneur de Jean Pictet (pp. 699-711). Ginebra: Comité International de la Croix-Rouge-Martinus Nijhoff Publishers.

Hailbronner, K. (1993). The Concept of Safe Country and Expeditious Asylum Procedures: A Western European Perspective. International Journal of Refugee Law (5), 31-66.

IOM (2004). Glossary on Migration. International Migration Law. Geneva: IOM.

Mariño, F. M. (2015). Recent Jurisprudence of the United Nations Committee against Torture and the International Protection of Refugees. Refugee Survey Quarterly (34), 61-78.

McAdam, J. (2011). An Intellectual History of Freedom of Movement in International Law: The Right to Leave as a Personal Liberty. Melbourne Journal of International Law (12), 27-56. 
Mezzadra, S. y Nielson, B. (2014). Fronteras de inclusión diferencial. Subjetividad y luchas en el umbral de los excesos de justicia. Papeles del CEIC (2).

Morgades, S. (2016). Refugiado. Eunomía: Revista en Cultura de la Legalidad (10), 231-249.

Naïr, S. (2016). Refugiados. Frente a la catástrofe humanitaria, una solución real. Barcelona: Planeta.

Oberoi, P., Taylor-Nicholson, E. (2013). The Enemy at the Gates: international Borders, Migration and Human Rights. Laws (2, 3), 169-186.

Orejudo, P. (2017). El concepto de "país seguro" y otros dispositivos restrictivos del derecho de asilo en España y la Unión Europea. Cursos de Derecho internacional y relaciones internacionales de Vitoria-Gasteiz $=$ VitoriaGasteizko nazioarteko zuzenbide eta nazioarteko herremanen ikastaroak (1), 435-486.

Peers, S. (2016). EU Justice and Home Affairs Law. Vol I. EU Immigration and Asylum Law. Oxford: Oxford University Press.

Pons, X. (coord.) (1998). La Declaración Universal de Derechos Humanos. Comentario artículo por artículo. Barcelona: Icaria-Antrzyt.

Sassen, S. (2013). Inmigrantes y ciudadanos. De las migraciones masivas a la Europa fortaleza. España: Siglo XXI.

Sassen, S. (2014). Expulsions: Brutality and Complexity in the Global Economy. Harvard: Harvard University Press.

Solanes, A. (2014). Derechos Humanos y asilo sobre las deficiencias del SECA y la regulación jurídica española. Anuario de la Facultad de Derecho (UAH) (7), 181-210.

Solanes, A. (2016). Una reflexión iusfilosófica y política sobre las fronteras. Anuario de Filosofia del Derecho (32), 145-184.

Solanes, A. (2017). Contra la normalización de la ilegalidad: la protección judicial de los extranjeros frente a las expulsiones colectivas y las devoluciones "en caliente". Cuadernos Electrónicos de Filosofía del Derecho (36), 43-73. 
Solanes, A., Delipetrou, D. (2017). Problems and proposals regarding the Common European Asylum Sistem: the example of Greece. Valencia: Tirant lo Blanch.

Vedsted-Hansen, J. (2015). Compilación de Derecho de las personas refugiadas. Casos, documentos y materiales. Budapest: Comité Húngaro de Helsinki. 